\title{
Functional response and potential impact of invertebrate predators on benthic fish eggs: analysis of the Calliopius laeviusculus-capelin (Mallotus villosus) predator-prey system*
}

\author{
E. M. DeBlois, W. C. Leggett \\ Department of Biology, McGill University, 1205 Ave. Dr. Penfield, Montreal, Quebec, Canada H3A 1B1
}

\begin{abstract}
We studied predation by a tidal migrant, Calliopius laeviusculus (Amphipoda: Gammaridea) on the eggs of beach-spawning capelin Mallotus villosus. Handling time did not constrain predation. Attack rate, mediated by search time and gut fullness, and assessed here through functional response trials and gut filling/clearance rate experiments, determined the magnitude of predation on capelin eggs. The relationship between egg density and egg consumption was sigmoid. Compensatory mortality occurred over an egg density range of ca 1 to 3 eggs $\mathrm{cm}^{-3}$ At these low egg densities compensatory mortality should only have a small stabilizing influence on capelin egg survival. At higher egg densities, attack rate declined with egg density. Satiation occurred at ca 11 eggs amphipod ${ }^{-1}$ At surplus egg density, gut filling rate experiments showed that satiation is possible within $2 \mathrm{~h}$ and functional response trials indicated that average egg densities found in situ $\left(40 \mathrm{egg} \mathrm{cm}{ }^{-3}\right)$ are sufficiently high to allow satiation within this time period. Gut clearance required $36 \mathrm{~h}$. Tidal periodicity should not constrain amphipod predation on capelin eggs. We suggest that predation by C. laeviusculus on the intertidal eggs of capelin can have an important influence on egg abundance. We calculated that C. Iaeviusculus could consume roughly $39 \%$ of capelin egg production. We speculate that predation by gammarids and other invertebrates on subtidal fish eggs should be higher owing to longer egg development times, and therefore exposure to predation, which occur at lower incubation temperatures in deeper water. Predation by small invertebrates on demersal fish eggs may therefore be an important regulator of population size in many marine fish species.
\end{abstract}

\section{INTRODUCTION}

Predation on early life history stages of marine fish can be an important mechanism of density regulation in fish populations (Peterman 1977. Hilden 1988). Studies of predation mortality during the early life history of marine fish have focussed primarily on pelagic fish eggs and larvae (reviewed in Bailey \& Houde 1989) for which rapid dispersal prevails. Few studies have quantitatively examined the importance of predation on benthic fish eggs (Frank \& Leggett 1984) which normally develop in dense aggregations.

Aggregation should render benthic fish eggs particularly vulnerable to predation (Dalberg 1979). Egg

- Contribution to the program of GIROQ (Groupe interuniversitaire de recherches océanographiques du Québec) patches produced by mass spawnings have, in fact, been shown to offer exceptional feeding opportunities to predators (Frank \& Leggett 1984, McGurk 1986, 1987). At a much more general level, prey aggregations are widely known to attract large numbers of predators, and aggregated prey can suffer intense predation mortality under these circumstances (Murdoch \& Oaten 1975. Hassell 1978, Sih 1984).

To date, most studies addressing predation on benthic fish eggs have concentrated on gut content analysis, the primary aim being to identify potential fish predators (see review in Frank \& Leggett 1984). Mortality estimates ranging from 1.6 to $40 \%$ of the annual egg production have been reported in the few studies estimating benthic egg predation by fish (Dragundsund \& Nakken 1973, Hunter \& Kimbrell 1980 , Frank \& Leggett 1984).

The role of invertebrates as predators on benthic fish 
eggs has been largely ignored (Nikolskii 1969). One exception, Palsson (1984), concluded that predation by small invertebrates (snails and caprellid amphipods) could account for the observed 16.9 to $51.8 \%$ egg loss in benthic spawning herring Clupea pallasi.

In this paper we report a series of experiments designed to quantify the character and magnitude of predation by the amphipod, Calliopius laeviusculus, on the eggs of capelin Mallotus villosus.

\section{MATERIALS AND METHODS}

Study system. The limited number of quantitative estimates of predation on eggs of benthic spawning marine fishes results largely from logistic difficulties related to locating and studying predator-prey interactions on offshore spawning beds (Frank \& Leggett 1984). The ease of access to capelin eggs, which are spawned intertidally, offers an excellent system within which to study the influence of egg aggregation on predation mortality.

In June and early July, schools of mature capelin spawn on hundreds of beaches on the coast of Newfoundland. The eggs, which adhere to beach gravel, become distributed from the high to low tide zone and occur homogeneously to a depth of $12 \mathrm{~cm}$ in the beach gravel. Hatching occurs 2 to 3 wk after spawning (Frank \& Leggett 1981). The amphipod Calliopius laeviusculus is an epibenthic tidal migrant (Fincham 1970, Daag 1976, Hudon 1983). We typically found C. laeviusculus at a water depth of 0.5 to $2 \mathrm{~m}$ along capelin spawning beaches. These amphipods were abundant on all 10 of the capelin spawning beaches we examined on the western coast of Conception Bay, Newfoundland.

All experiments were conducted at Bryant's Cove, Newfoundland, where capelin regularly spawn. Bryant's Cove beach is representative of a large number of capelin spawning beaches along the east coast of Newfoundland in both sediment configuration laverage particle size $=1$ to $4 \mathrm{~mm}$; B. S. Nakashima, Dept Fish. Oceans, St. Johns, Nfld, pers. Comm.) and capelin egg density (Taggart \& Nakashima 1987). This latter study showed that variation in capelin egg density was greater among years than within years among beaches. Stock discrimination studies have shown that beachspawning capelin on Newfoundland's east coast are from a single stock (Sharp et al. 1978, Misra \& Carscadden 1984), indicating that egg densities noted on Bryant's Cove in any given year should prevail over a wide geographical area.

Frank \& Leggett (1981) reported that capelin eggs on Bryant's Cove had an average density of 38.9 eggs $\mathrm{cm}^{-3}(\mathrm{SE}=3.9)$ during the egg development period and reached a maximum average density of 75.9 eggs
$\mathrm{cm}^{-3}(\mathrm{SE}=10.0)$ following spawning. We found $\mathrm{Cal}$ liopius leaviusculus density over capelin spawning beds to be ca 1 amphipod $\mathrm{cm}^{-2}$ (SE $=0.20$ ).

Predation experiments. We designed experiments to assess the functional response of Calliopius laeviusculus to capelin egg density. Numerous studies have shown that predator consumption increases with prey density, eventually reaching a maximum at high prey density. The Ivlev curve (Ivlev 1961), a negative exponential model, has often been used to describe this impact of predator on prey, and also the influence of food concentration on consumption and growth (Houde \& Schekter 1980, Werner \& Blaxter 1981, Munk \& Kiørboe 1985, Mackenzie et al. 1990). The Ivlev curve is represented by the equation:

$$
N e=a\left(1-e^{-c N a}\right)
$$

where $\mathrm{Ne}=$ number of prey eaten; $\mathrm{Na}=$ number of prey available; a defines maximum consumption, and $c$ the rate at which maximum consumption is reached.

The Ivlev model can only describe curvilinear relationships and does not provide any insight into the mechanisms responsible for the feeding patterns observed

Holling (1959) proposed a series of mechanistic predation/parasitism models, describing linear, curvilinear and sigmoid functions, that, when fitted to results from functional response experiments, roughly segregate predation into 2 components: handling time per prey, and attack rate. Attack rate is a function of search time (which reflects the ability of a predator to detect and capture prey) and/or gut filling rate and ultimately satiation which determine a predator's predisposition to feed.

A key requirement for correct parameterization using Holling models is the maintenance of constant prey density during experiments. Most predation experiments do not meet with this requirement. Integrated forms of Holling's predator equations have been proposed to correct for prey depletion (e.g. Royama 1971, Rogers 1972, Hassell et al. 1977). These methods have been shown to give highly biased parameters and therefore lead to unreliable conclusions (Juliano \& Williams 1987).

Because of these problems associated with parameter estimation when using mechanistic predation models, we chose to independently assess handling time and attack rate. Attack rate was estimated indirectly, at satiation prey density, through experiments which examined gut filling and clearance rates.

While parameter estimates based on functional response curves often lead to false interpretation of the mechanism driving the response, delineation of the shape of the response curve (linear, curvilinear or sigmoid) does allow detection and definition of density- 
dependent predation. Specifically, positive density dependence (density compensation), characterized by a sigmoid functional response, can have a strong stabilizing effect on prey population density (see Peterman 1977, for an extensive discussion on density compensation and recruitment stability).

To identify the shape of the functional response, we performed a weighted least squares regression on logit-transformed values of predation rate versus logtranformed values of prey density (see Trexler et al. 1988 for details on method). The logit transform was:

$$
y_{1}=\ln \left[N e /\left(N a_{1}-N e_{1}\right)\right]
$$

where $N e_{i}=$ number of prey eaten at the $i^{\text {th }}$ level of prey available $\left(N a_{i}\right)$.

This method accurately identifies the presence and location of positive density dependence (Trexler et al. 1988). However, since the meaning of highly transformed variables required by this analysis is not intuitively obvious, we also calculated a weighted (weight $=1 /$ dens. ${ }^{2}$ ) nonlinear regression (proc nlin; SAS 1985) using untransformed data. This regression decribed the relationship between total prey consumption and prey density.

Relevant parameters from these experiments were combined to generate an estimate of the magnitude of amphipod predation on capelin eggs.

Influence of circadian feeding and temperature on Calliopius laeviusculus egg consumption. Many factors could influence amphipod feeding behavior. Of these, we hypothesized that diurnal feeding and changes in feeding rate with temperature could have a large influence on estimates of the impact of amphipod predation on capelin eggs. These factors were therefore studied directly by experiments.

Trials were executed to identify and quantify circadian feeding in amphipods. We did not address the mechanisms (visual feeding, endogenous rhythm) underlying a possible feeding cycle. We examined feeding in 2 asynchronous experiments which replicated conditions in situ: amphipods were subjected to light levels consistent with time of day. Predation experiments were run from 12:00 to 20:00 h (July 9, 1988), under daylight conditions and from 22:00 to 06:00 h (July 9/10, 1988), under continuous darkness. At the onset of both experiments, 10 amphipods ( 4 to 6 $\mathrm{mm}$ in length), starved for $24 \mathrm{~h}$, were given a surplus of eggs (200 eggs per $100 \mathrm{ml}$ container). Amphipods were then allowed to feed on these eggs for time intervals ranging from 1 to $8 \mathrm{~h}$ (time levels were: $1,2,3,4,5,6,7$, and $8 \mathrm{~h}$ ). Each time level was replicated 4 times. Both experiments were run at $8^{\circ} \mathrm{C}$. We combined the 2 experiments into a treatment variable in an ANOVA assessing the influence day and night on feeding over time intervals ranging from 1 to $8 \mathrm{~h}$.
We assessed the influence of temperature on feeding in experiments conducted in Montreal, Quebec, using amphipods and capelin eggs transported from Newfoundland. Single amphipods, held in aerated $100 \mathrm{ml}$ beakers, were exposed to a temperature gradient ranging from 5 to $14^{\circ} \mathrm{C}$ at $1{ }^{\circ} \mathrm{C}$ intervals. Each temperature level was replicated 4 times. Amphipods were given 10 eggs per 48 h, over 2 separate 48 h periods (October 17 to 19 and 19 to 21,1989 ). After the first $48 \mathrm{~h}$ period, uneaten and punctured eggs were collected and counted and a fresh supply of eggs was provided. At the end of the second period all uneaten and punctured eggs were again enumerated. Amphipods used in these experiments were all ca $30 \mathrm{~d}$ old (average size at age $30 \mathrm{~d}=3.8 \mathrm{~mm}$ ). The influence of temperature on the number of eggs eaten per $48 \mathrm{~h}$ period was assessed through least squares regression.

Handling time trials. We define the handling time of a capelin egg by an amphipod as the time interval from the piercing of the chorionic membrane to the complete removal of the egg contents. Preliminary observations showed that amphipods do not consume the chorionic membrane of either naturally or artificially spawned capelin eggs. Rather, they pierce the chorion with Gnathopod 1 and then use gnathopods and Peraeopods 3 and 4 to squeeze the egg contents toward the mouthparts. We found capelin eggs in situ with punctures characteristic of Calliopius laeviusculus predation.

Handling time was assessed by direct observation under a dissection microscope. We performed 50 trials. In each, 1 amphipod and clumps of 5 to 10 eggs, both obtained from the beach at Bryant's Cove, were placed in a $3 \mathrm{~cm}$ (diameter) by $0.5 \mathrm{~cm}$ (depth) petri dish filled with seawater. All amphipods were starved for $24 \mathrm{~h}$ before initiating the trials. The size (total length) of amphipods used in each trial was measured using an ocular micrometer. The trials were run at temperatures ranging from 15 to $22^{\circ} \mathrm{C}$. We excluded observations taken at temperatures ranging from 19 to $22^{\circ} \mathrm{C}(\mathrm{n}=4)$ from our analysis because handling times were much lower at these temperatures than handling times noted over the 15 to $19^{\circ} \mathrm{C}$ temperature range $(n=22)$ and because these temperatures never occur in situ. We also excluded those trials in which the attacked egg was not completely consumed $(n=24)$. We did so because we preferred to overestimate rather than underestimate handling time. Overestimation, if it occurred, results in conservative estimates of predation loss. We assessed the influence of amphipod size and temperature $\left(15\right.$ to $19^{\circ} \mathrm{C}$ ) on handling time independently through least squares regression

Functional response trials. Experimental system: Functional response experiments were carried out in 11 circular containers (height: $10 \mathrm{~cm}$, cross sectional area: $100 \mathrm{~cm}^{2}$ ) fitted, at $3 \mathrm{~cm}$ height and on opposite 
sides, with two $5 \times 8 \mathrm{~cm} 53 \mu \mathrm{m}$ Nitex windows to allow water exchange. These containers were immersed in aerated $25 \mathrm{l}$ aquaria containing fresh unfiltered seawater from the nearshore area of Bryant's Cove. Constant water temperatures were maintained in the aquaria by placing them in a temperature-regulated freshwater bath.

All capelin eggs used in the experiments were obtained by artificially spawning naturally ripened fish collected in June 1988 (see Chambers \& Leggett 1989 for details). Fertilized eggs were coated with diatomaceous earth to prevent adhesion and to facilitate counting (Smigielski \& Arnold 1972). Hourly observations were made, over 3 consecutive days, of amphipods simultaneously offered sediment patches containing eggs that were either coated or uncoated with diatomaceous earth. An ANOVA on amphipod number on egg patches (corrected for day, time of day and day $x$ time interaction) showed no difference in amphipod number on coated and uncoated egg patches $\left(F_{1,135}=0.34, \mathrm{p}>0.6\right)$. We also noted a similar method of consumption (described above in 'Handling time trials') for eggs coated with diatomaceous earth and uncoated eggs.

The number of eggs used in each trial was determined volumetrically (number per unit volume) following empirical determination of this relationship. Eggs were also weighed and density treatments were allocated equally to experimental and control (without predators) groups for later and more precise calibration of initial egg number. The eggs were mixed to a depth of $0.5 \mathrm{~cm}$ with $50 \mathrm{~cm}^{3}$ of egg-free beach gravel (1 to $4 \mathrm{~mm}$ diameter) obtained from the local beach. The epibenthic life mode of Calliopius leaviusculus precluded the need to use a $12 \mathrm{~cm}$ egg/sediment layer as found in situ. Under natural conditions, there is evidence that wave activity continuously redistributes eggs and sediment homogeneously throughout the deposition layer (Frank \& Leggett 1981), supplying the surface sediment layer and therefore amphipods with egg densities that are consistent over the entire capelin spawning bed. To more adequately represent field conditions in our experiments, naturally occurring benthic animals (mainly oligochaetes and maggots of the beach fly Fucellaria), which could provide amphipods with alternative prey, were not removed from the sediment used. Since sediment was taken directly from the spawning beach and stirred to produce a homogeneous mixture, alternative prey densities were those found in situ.

Amphipods were captured 24 h before each of 3 trials (June 21, June 28 and July 5, 1988) and held under natural photoperiod, without food, in an outdoor tank supplied with running seawater. Mean (SD) amphipod size for Trials 1 through 3 was $5.6 \mathrm{~mm}$ (1.5), $5.6 \mathrm{~mm}$
(1.0) and $5.3 \mathrm{~mm} \mathrm{(0.9)} \mathrm{respectively.} \mathrm{The} \mathrm{range} \mathrm{of}$ amphipod sizes in the trials was 3.5 to $8 \mathrm{~mm}$. Amphipods larger than $8 \mathrm{~mm}$ were uncommon in our collections and were not used in functional response trials because preliminary observations showed a high frequency of mating at the expense of feeding in this group. Amphipods were acclimated for $1 \mathrm{~h}$ in glass vials suspended in the experimental containers before initiation of each experiment.

Experimental design: Eight egg densities were tested. These ranged from ca 1 to $80 \mathrm{~cm}^{-3}$ in a logarithmic series and were consistent with natural beach densities (Table 1). Egg density levels were arranged in a split plot design (Freund \& Littell 1981) with predation (predators absent or present at density $=0.75$ $\mathrm{cm}^{-2}$ ) tested over main plots (aquaria) and density tested over subplots (containers) within aquaria. The density treatment was replicated 10 times.

During the first experiment (June 21, 1988), the temperature ranged between 14.0 and $15.0^{\circ} \mathrm{C}$. During the remaining 2 experiments (June 28 and July 5, 1988) temperatures ranged between 7.0 and $8.0^{\circ} \mathrm{C}$. The June 21 and 28 experiments were performed from 12:00 to 20:00 h under daylight conditions. The length of these experiments represents the average duration of tidal inundation (exposure to amphipod predation) for intertidal capelin eggs. The July 5 experiment ran from 17:00 h on June 5 to $17: 00 \mathrm{~h}$ on June 6 , under normal (16:8 L:D) photoperiod. The length of this experiment was set to assess whether an experimental duration of 8 $h$, matching the average time of tidal inundation, constrained predation on capelin eggs. We expected predation to be higher in the $24 \mathrm{~h}$ experiment if a feeding period of $8 \mathrm{~h}$ was insufficient.

A subsampling technique was used to determine post-trial egg numbers when egg number, as judged by visual inspection, was greater than 750 . The eggs

Table 1 Mallotus villosus. Average capelin egg numbers and densities used in functional response experiments. Average egg densities in situ range from 0 to 76 eggs $\mathrm{cm}^{-3}$ (Frank \& Leggett 1981). Amphipod density was fixed at 0 and 0.75 $\mathrm{cm}^{-2}$ Sediment volume in experimental containers was 50 $\mathrm{cm}^{3}$, surface area was $100 \mathrm{~cm}^{2}$

\begin{tabular}{|crc|}
\hline $\begin{array}{c}\text { Treatment } \\
\text { level }\end{array}$ & Egg no. & $\begin{array}{c}\text { Egg density } \\
\text { (no. cm }{ }^{-3} \text { ) }\end{array}$ \\
\hline 1 & 44 & 0.88 \\
2 & 84 & 1.68 \\
3 & 145 & 2.90 \\
4 & 290 & 5.80 \\
5 & 591 & 11.82 \\
6 & 1131 & 22.62 \\
7 & 2172 & 43.44 \\
8 & 3716 & 74.32 \\
\hline
\end{tabular}


were placed in a sucrose solution that rendered them neutrally buoyant. This mixture was stirred and subsampled in triplicate using a $1 \mathrm{~cm}$ diameter pipette. Subsamples were rejected and returned to the sucrose solution if they contained less then 150 eggs, or had CV's $(S D / \bar{x} \times 100)$ higher then $10 \%$ (see Van Guelpen et al. 1982). This technique yielded subsamples that conformed to a Poisson distribution $\left(\chi^{2}=0.2362\right.$, $\mathrm{df}=$ 19. $\mathrm{p}>0.5$ ) suggesting a random distribution of eggs in the sugar solution. We detected no bias between estimated and actual egg numbers $\left(\chi^{2}=1.42\right.$, df $=19$, $p>0.90)$. When final egg densities were assessed to be smaller than 750, all eggs were counted visually. Because we noted during handling time trials that amphipods often punctured eggs without completely consuming the contents, all counted eggs were individually checked for attack marks. In most .cases, when amphipods did not consume the entire egg content, at least half of the egg content was eaten. We did not quantify levels of prey consumption. Estimates of egg consumption in all experiments described in this study include these attacked but incompletely consumed eggs. In functional response trials, $7 \%$ (SE = $0.9 \%$ ) of all eggs designated as consumed were partially eaten.

In addition to the functional response analyses described previously, we examined the influence of egg density (number of eggs available to the predators $=\mathrm{Na}$ ) on the number of eggs eaten $(\mathrm{Ne})$ via a nested ANOVA. The influence of predation (predators present or absent) was tested over treatment within aquaria (see Freund \& Littell 1981).

To identify the occurrence of and the prey densities associated with maximum consumption, we generated an ANOVA on combined experiments using density and experiment ( 1 to 3 ) as main effect variables. We used contrast analysis (Sokal \& Rohlf 1981, p. 253-259) on egg consumption for the 3 highest densities (ca 20 , 40 and 75 eggs $\mathrm{cm}^{-3}$ ).

The influence of egg depletion on total egg consumption in the $24 \mathrm{~h}$ experiment was assessed by comparing expected egg consumption after $24 \mathrm{~h}$, given known consumption over $8 \mathrm{~h}$ periods, to observed egg consumption after $24 \mathrm{~h}$. Expected egg consumption $(\mathrm{Ne})$ at the end of $8 \mathrm{~h}$ time intervals $j$ (where $j=8,16,24 \mathrm{~h}$ ), as a function ( $f$ ) of $N a_{k}$ (where $N a$ is the number of eggs available at the beginning of a time interval $j$ and $k=0$ -8)) was calculated and used to reset $N a_{k}$ after each of three $8 \mathrm{~h}$ feeding periods over $24 \mathrm{~h}$ as follows:

$$
\begin{aligned}
& N e_{8}=f\left(N a_{0}\right) \\
& N e_{16}=f\left(N a_{0}-N e_{8}\right) \\
& N e_{24}=f\left(N a_{8}-N e_{16}\right)
\end{aligned}
$$

Estimates of cumulative consumption (after $24 \mathrm{~h}$ ) were generated as follows:

$$
N e_{\text {total }}=N e_{8}+N e_{16}+N e_{24}
$$

These estimates were then compared to observed results for the $24 \mathrm{~h}$ experiment.

Gut filling/clearance trials. Amphipod gut filling and clearance rates were estimated indirectly by providing amphipods (4 to $6 \mathrm{~mm}$ in length) with capelin eggs in sediment-free containers $(100 \mathrm{ml})$ and noting egg consumption after predetermined time intervals. To minimize the effect of search time, and to maximize feeding rates, amphipods were exposed to higher egg densities and a more homogeneous egg distribution than that found in situ.

The gut filling rate experiment was performed on July 6,1988 . In this experiment, 1 amphipod was isolated in a $100 \mathrm{ml}$ container and provided with 50 eggs. Egg consumption was then monitored after time periods ranging from 2 to $24 \mathrm{~h}$ from the initiation of the experiment (time levels were set at $2 \mathrm{~h}$ intervals and were: 2,4 , $6,8, \ldots 22,24 \mathrm{~h}$ ). Each level of this time treatment was replicated 5 times. The experiment was run at 7 to $8^{\circ} \mathrm{C}$.

Gut clearance was not measured directly. Precise estimates of gut evacuation time can be obtained through an examination of gut content reduction with time in pre-fed animals (see Boisclair \& Leggett 1988). This technique is not practical for amphipods (3 to 8 $\mathrm{mm}$ in length) fed transluscent capelin eggs. We evaluated clearance rate in experiments designed to identify feeding periodicity in amphipods allowed to feed at satiation levels. Feeding rates of satiated amphipods decline to relatively low levels and the length of the interval over which low feeding rates occur is related to gut clearance time.

Gut clearance was estimated in 2 discrete trials initiated on June 16 and June 27, 1989. Each trial had a duration of $5 \mathrm{~d}$. In Expt 1, each experimental unit consisted of 2 amphipods placed in a $100 \mathrm{ml}$ container and provided with 200 eggs. Amphipods were allowed to feed for time periods ranging from 12 to $120 \mathrm{~h}$ (time levels were set at $12 \mathrm{~h}$ intervals and were: 12, 24, 36, $48, \ldots 108$ and $120 \mathrm{~h}$ ). Each time level was replicated 5 times. Time periods ended at either 09:00 or 21:00 h. The experiment was conducted under normal (16:8 L:D) photoperiod. Expt 2 was similar in design but the number of amphipods and eggs per container was reduced to 1 and 100 respectively.

To delineate changes in feeding over time, the results of the gut filling and clearance experiments were expressed as hourly feeding rates over 2 and $12 \mathrm{~h}$ intervals respectively. Since we did not replenish eggs in the containers remaining at the end of each sampling period, we adjusted the egg number at the beginning of the subsequent time period by subtracting the average consumption in the previous periods from the initial egg number. 


\section{RESULTS}

Influence of circadian feeding and temperature on egg consumption

We could not detect any diurnal feeding cycle for Calliopius leaviusculus. There was no difference in egg consumption in experiments held from 12:00 to 20:00 h (daylight conditions) and from 22:00 to 06:00 h (night conditions) $\left(F_{1,55}=1.23, \mathrm{p}>0.2\right)$ (Fig. 1).

Over a temperature range 5 to $14^{\circ} \mathrm{C}$, the influence of temperature on the number of eggs eaten (corrected for both dates, Oct 17 to 19 , Oct 19 to 21 , and date $\times$ temperature interaction) was not significant (partial $\mathrm{R}^{2}$ $=0.036, F_{1.76}=3.45, \mathrm{p}>0.06$ ) Further, contrast analysis among temperatures showed that only at a temperature of $5^{\circ} \mathrm{C}$ was consumption (total number eaten) different $\left(F_{1.60}=6.95, \mathrm{p}<0.05\right)$ and lower than consumption values noted at the other tested temperatures. We cannot claim that temperature has no effect on consumption rates. However the influence of temperatures ranging from 6 to $14^{\circ} \mathrm{C}$ on Calliopius laeviusculus egg consumption, if present, was too small to be detected under these experimental conditions.

\section{Handling time trials}

The time required for an amphipod to consume a single egg ranged from 0.2 to $5 \min (\overline{\mathrm{x}}=2.37, \mathrm{n}=22$, $\mathrm{SE}=0.67$ ). Temperature had no detectable influence on handling time over the range of temperatures used in these measurements $\left(15\right.$ to $\left.19^{\circ} \mathrm{C}\right),\left(F_{1,20}=0.77, \mathrm{R}^{2}=\right.$ $0.04, \mathrm{p}>0.4$ ). Amphipod size (range 3.5 to $9 \mathrm{~cm}$ ) significantly affected handling time $\left(F_{1.20}=31.40, \mathrm{R}^{2}=\right.$ $0.62, \mathrm{p}<0.0001)$. Handling time decreased nonlinearly with amphipod size (Fig. 2). Amphipods used in the functional response experiments ranged from 3.5 to 8 $\mathrm{mm}$ in size. Over this size range, the average handling time was $2.6 \mathrm{~min}(\mathrm{SE}=0.3$ ). Based on handling time alone, we predicted that maximum consumption would not exceed 185 eggs amphipod ${ }^{-1}$ in the $8 \mathrm{~h}$ functional response experiments and 555 eggs amphipod ${ }^{-1}$ in the 24 h experiments.

\section{Functional response to egg density}

Both the presence of predators and initial egg number significantly influenced egg mortality at all prey densities, and in all 3 experiments. No block (aquaria) effect was noted (Table 2). Average consumption rate $( \pm 95 \%$ CI) was $48 \%(7 \%), 63 \%(10 \%)$ and $67 \%(8 \%)$ in functional response Expts 1, 2 and 3 respectively.

The relationship between initial egg density ( $N a)$ and numbers eaten $(\mathrm{Ne})$ was sigmoid. Forward selection least squares regression (SAS 1985) was executed on logit-transformed predation rate versus $X_{1}$ (log prey density), $X_{2}$ (square of $\log$ prey density) and $X_{3}$ (dummy variable representing Expts 1 through 3). The quadratic term $X_{2}$ was highly significant $\left(F_{2,117}=\right.$ 269.54, $\mathrm{p}<0.0001$ ). The experiment variable $X_{3}$ was not retained in the model at a critical significance level for entry in the model of $\alpha<0.5$ ) (Fig. 3)

We performed a lack of fit test (Neter et al. 1985, p. 123-132) on both 1-parameter $\left(y=b X_{1}\right.$, where $X_{1}=$ $\log$ density) and 2-parameter ( $y=b_{1} X_{1}+b_{2} X_{2}$, where $X_{2}=\log$ density squared) models. Because the above regression showed no strong difference among experiments, we combined results of Expts 1 through 3 and divided density treatments into 8 distinct categories

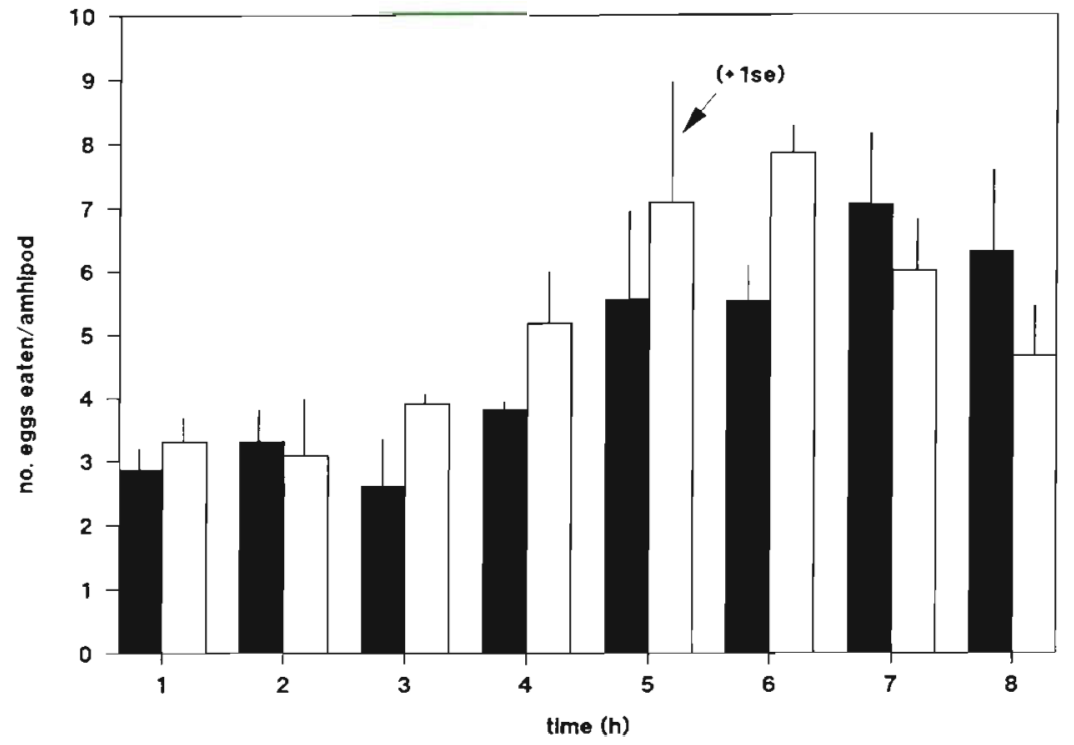

Fig. 1. Calliopius laeviusculus. Cumulative amphipod egg consumption over 8 h periods from 12:00 to $20: 00 \mathrm{~h}$ under daylight conditions (open bars) and from 22:00 to $06: 00 \mathrm{~h}$ under total darkness (black bars) 
Fig. 2. Calliopius laeviusculus. Relationship between handling time and amphipod size superimposed on size distribution (histogram) from June to August in Conception Bay, Newfoundland (from Steele \& Steele 1973)

based on average initial egg number over all 3 experiments. We rejected the null hypothesis that the estimated model represented the true regression equation for the 1-parameter model $\left(F_{6,113}=5.38, \mathrm{p}<0.05\right)$. The 2-parameter model provided a good fit to the data $\left(F_{5.113}=1.08, \mathrm{p}>0.10\right)$.

Although differences among experiments were small, we performed logit regression on each experiment separately to identify any difference in the location of compensatory predation along the prey density axis. Regression equations for Expts 2 and 3 showed that predation was compensatory at the 2 lowest tested densities, 0.88 to 1.68 eggs $\mathrm{cm}^{-3}$, and depensatory (predation rate decreased with density; consumption increased curvilinearly) thereafter. In Expt 1, compensatory mortality occurred up to 2.90 eggs $\mathrm{cm}^{-3}$, the next highest density.

Since compensation occurred only over a small range, and only at the lowest tested densities, the relationship between initial egg density and the number of eggs eaten per amphipod was adequately characterized (Fig. 4) by the negative exponential curve derived from Eq. (1).

Maximum consumption (parameter a) in all 3 experiments occurred at an average of $10.83( \pm 95 \% \mathrm{CI}=$ 0.14) eggs amphipod ${ }^{-1}$. Maximum consumption

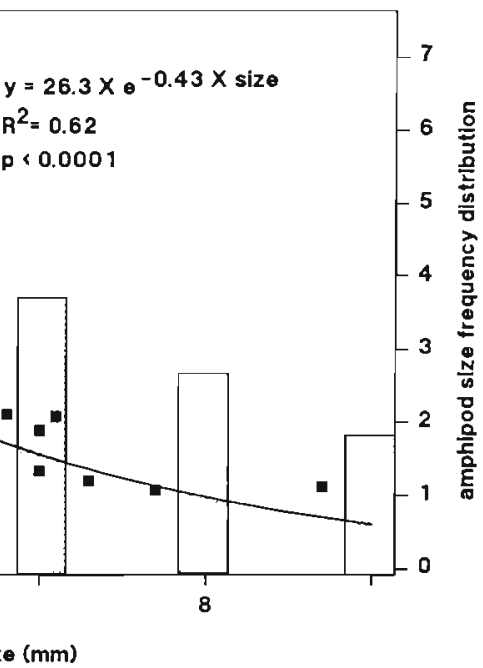

( $\pm 95 \% \mathrm{CI}$ ) was $12.76(2.14), 9.28$ (1.68), and 12.29 (2.9) eggs amphipod ${ }^{-1}$ for Expts 1 through 3 respectively. An ANOVA on consumption at densities equal to or greater than 40 egg $\mathrm{cm}^{-3}$ again revealed no difference in consumption between $8 \mathrm{~h}$ and $24 \mathrm{~h}$ experiments $\left(F_{2,26}=1.17, p>0.3\right.$, power 0.33$)$. The power of this test was low, however, (see Cohen 1981 on power analysis) and egg depletion over 24 h may have reduced consumption sufficiently to produce the observed results.

The possible influence of egg depletion on parameter a was assessed by generating expected consumption values at $8 \mathrm{~h}$ intervals over $24 \mathrm{~h}$. The number of eggs available $(\mathrm{Na})$ at the beginning of each $8 \mathrm{~h}$ interval was adjusted for consumption over the previous interval, thereby accounting for depletion of prey. Consumption values over $8 \mathrm{~h}$ intervals were generated from parameter estimates ( $a$ and $c$ ) for $8 \mathrm{~h}$ Expts 1 and 2 combined:

$$
N e_{j}=10.83\left(1-\mathrm{e}^{-0.05 N a_{j}}\right)
$$

where $N e_{j}=$ number of eggs eaten at the end of the $j^{\text {th }}$ time interval; $N a_{k}=$ number of eggs available at the beginning of the $j^{\text {th }}$ interval $(k=j-8) ; j$ represents $8 \mathrm{~h}$ intervais $(j=8,16,24 \mathrm{~h}) ; N a_{k}=N a_{k-8}-N e_{j}$.

Total consumption over $24 \mathrm{~h}$ was predicted from Eq. (3).

Table 2. Analysis of variance of functional response Expts 1 to 3 . Treatment (predator present or absent) is tested over treatment nested within aquaria [B(treatment)] (Freund \& Littell 1981)

\begin{tabular}{|c|c|c|c|c|c|c|c|}
\hline \multirow[t]{2}{*}{ Source } & \multirow[t]{2}{*}{$\mathrm{df}$} & \multicolumn{2}{|c|}{ June 21} & \multicolumn{2}{|c|}{ June 26} & \multicolumn{2}{|c|}{ July 5} \\
\hline & & $F$ & $\mathrm{p}$ & $F$ & $\mathrm{p}$ & $F$ & $\mathrm{p}$ \\
\hline Treatment & 1 & 51.72 & 0.0001 & 109.98 & 0.0001 & 750.10 & 0.0001 \\
\hline $\mathrm{B}$ (Treatment) & 8 & 0.97 & 0.4695 & 0.92 & 0.5079 & 0.42 & 0.9021 \\
\hline Egg density & 7 & 8.71 & 0.0001 & 84.32 & 0.0001 & 1685.98 & 0.0001 \\
\hline Treatment $\times$ Egg density & 7 & 4.89 & 0.0002 & 9.06 & 0.0001 & 24.50 & 0.0001 \\
\hline Error & 56 & - & - & - & - & - & - \\
\hline
\end{tabular}




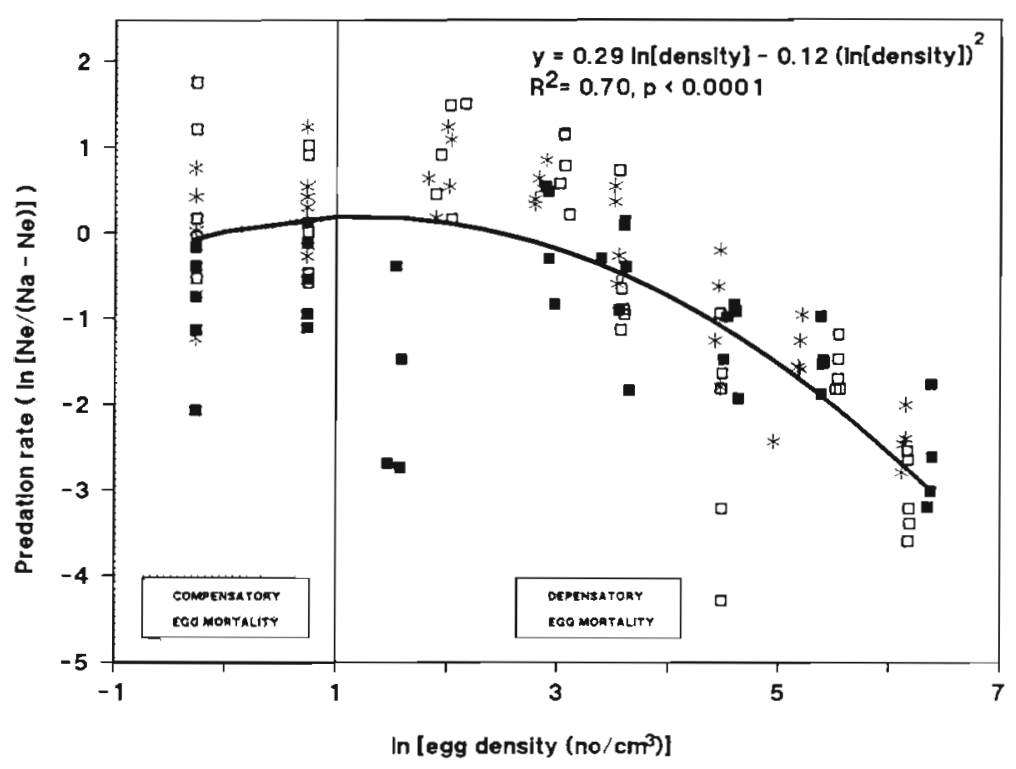

Fig. 3. Regression model combining results of functional Expts 1,2 and 3. This regression employs logit-transformed values of predation rate on $\ln ($ prey density). Symbols identify Expts $1(G)$, $2(*)$ and $3(*)$. Shaded area indicates zone of compensatory egg mortality
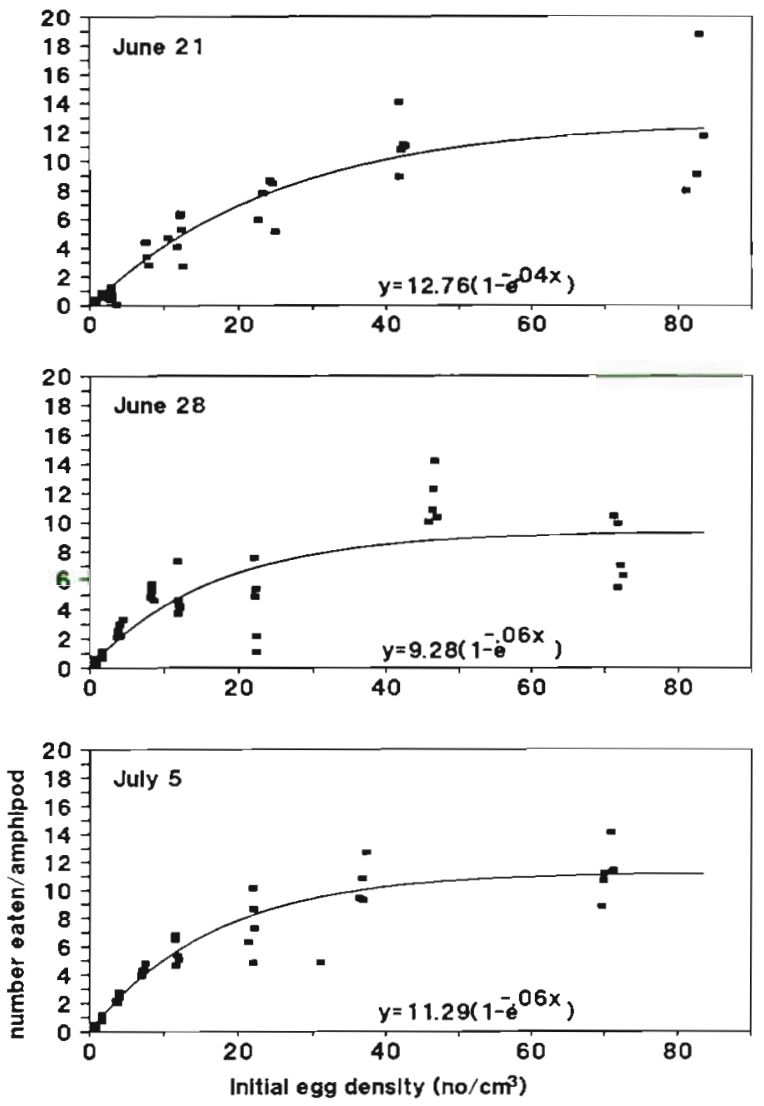

Fig. 4. Relationship, expressed as a negative exponential model, between number of eggs eaten and initial egg density for functional response Expts 1 to 3. Models explained 86, 69 and $89 \%$ of the variation in observed values for Expts 1, 2 and 3 respectively $(\mathrm{p}<0.0001$ in all cases)
The relationship between predicted $N e_{\text {total }}$ and $N a_{0}$ was assessed through nonlinear regression (proc nlin, SAS 1985).

Given known consumption over $8 \mathrm{~h}$ intervals, egg depletion over $24 \mathrm{~h}$ should have generated a maximum consumption, $a_{\text {, of }} 32.5$ eggs amphipod ${ }^{-1}$. This value differs significantly from the observed maximum consumption estimate of $12.29( \pm 95 \% \mathrm{CI}=2.9)(\mathrm{t}=12.56$, $\mathrm{df}=38, \mathrm{p}<0.0001)$. Maximum consumption in $24 \mathrm{~h}$ experiments was thus much lower than expected and approximated consumption values obtained after $8 \mathrm{~h}$. In addition, maximum consumption in both 8 and $24 \mathrm{~h}$ experiments was dramatically less than the values predicted from handling time trials: 185 eggs amphipod ${ }^{-1}$ and 555 eggs amphipod $^{-1}$ for 8 and 24 h trials respectively. We conclude that the duration of the experiments did not constrain predation at high prey densities and that amphipods were satiated within $8 \mathrm{~h}$ after having eaten ca 11 eggs.

Consumption increased with egg density up to a density of ca 40 eggs $\mathrm{cm}^{-3}$. The increase in consumption between egg densities of 20 and 40 eggs $\mathrm{cm}^{-3}$ is highly significant $\left(F_{1,110}=70.53, \mathrm{p}<0.0001\right)$ but no detectable difference in consumption occurred between 40 and 75 eggs $\mathrm{cm}^{-3}\left(F_{1.110} 2.49, \mathrm{p}>0.1\right)$. This suggests that egg consumption is limited by satiation at densities above ca 40 eggs $\mathrm{cm}^{-3}$.

There was no evidence that amphipods continued feeding after $8 \mathrm{~h}$ at egg densities below satiation level. The rates of approach (c) to the asymptote, where satiation is not yet reached, overlap in all 3 experiments. Consumption at densities below 40 eggs $\mathrm{cm}^{-3}$ did not differ $\left(F_{2,82}=0.64, \mathrm{p}>0.5\right.$, power $\left.=0.25\right)$. From $8 \mathrm{~h}$ 
Fig. 5. Calliopius laeviusculus. Amphipod feeding rate (eggs $\mathrm{h}^{-1}$ ) versus time over $24 \mathrm{~h}$. Containers (treatment levels) were collected at $2 \mathrm{~h}$ intervals starting at 10:00 h. There is a significant decrease in feeding rate after $8 \mathrm{~h}\left(F_{1,58}=12.12, \mathrm{p}<0.001\right)$ Feeding rate over the first $2 \mathrm{~h}$ period is higher than during all other time periods $\left(F_{1.48}=5.02\right.$,

$$
p<0.05)
$$

experiments, the predicted rate of approach to an asymptote of $a=10.83$ eggs amphipod ${ }^{-1}$, given depletion over $24 \mathrm{~h}$, is $c=0.15$. This value differs significantly from the observed rate of $0.06( \pm 95 \% \mathrm{CI}=0.015)(\mathrm{t}=$ 9.4, df $=78, \mathrm{p}<.0001)$ for the $24 \mathrm{~h}$ experiment.

\section{Gut filling and clearance rates}

The rate of gut filling declined over $24 \mathrm{~h}$ (Fig 5). There was a significant decrease in feeding after $8 \mathrm{~h}\left(F_{1,58}=\right.$ 12.12, $\mathrm{p}<0.001$ ), consistent with functional response experiments. Feeding rate over the first $2 \mathrm{~h}$ interval was high (ca 6 eggs amphipod ${ }^{-1} \mathrm{~h}^{-1}$ ) and differed from rates observed subsequently $\left(F_{1,48}=5.02, p<0.05\right)$ suggesting that, in this experiment, most feeding activity occurred within the first $2 \mathrm{~h}$ period. From gut clearance experiments we noted that high feeding rates reoccurred at 24 to $48 \mathrm{~h}$ intervals giving an average gut clearance time of $36 \mathrm{~h}$ (Fig. 6). The long-term hourly feeding rate from gut clearance experiments was 0.42 $( \pm 95 \% \mathrm{Cl}=0.35)$ and $0.48( \pm 95 \% \mathrm{Cl}=0.26)$ eggs amphipod ${ }^{-1} \mathrm{~h}^{-1}$ for gut clearance rate Expts 1 and 2 respectively. This is equivalent to 10.08 and 11.52 eggs amphipod ${ }^{-1} \mathrm{~d}^{-1}$ and is consistent with the results of the functional response experiments.

\section{DISCUSSION}

Over the range of capelin egg densities we evaluated ( 1 to 80 eggs $\mathrm{cm}^{-3}$ ), the relationship between the number of eggs consumed by Calliopius laeviusculus and egg density was sigmoid. Invertebrate predators of pelagic fish eggs or larvae typically exhibit a nonsigmoid' curvilinear increase in consumption with prey
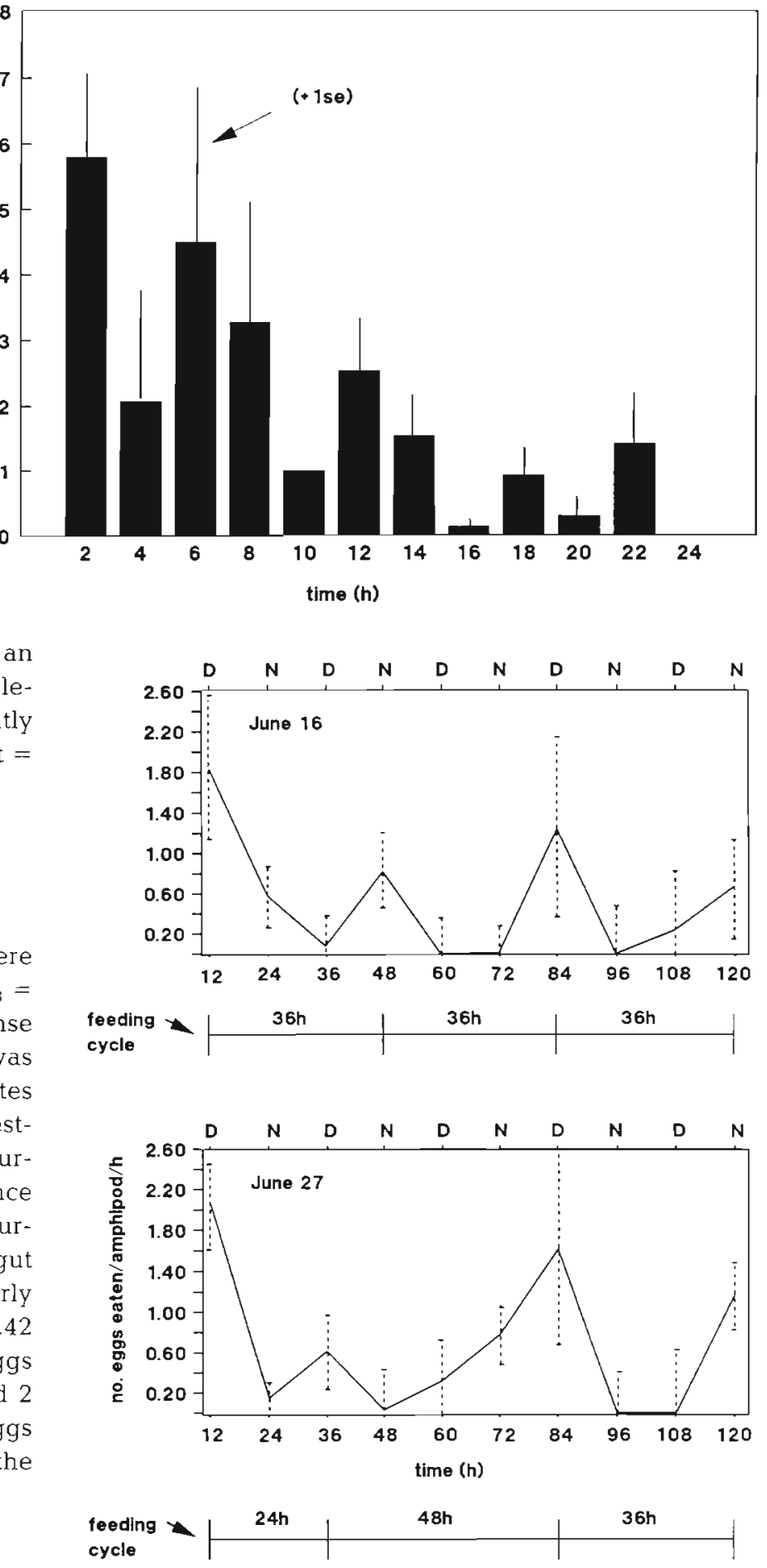

Fig. 6. Calliopius laeviusculus. Average amphipod feeding rate (eggs $\mathrm{h}^{-1}$ ) versus time over $120 \mathrm{~h}$. Dotted lines show standard error on means. In both experiments (June 16, June 27), collections were made at $12 \mathrm{~h}$ intervals (09:00 and 21:00 h) starting with a collection at 21:00 h. The top axis indicates night (N) and day (D) feeding. An average feeding cycle of $36 \mathrm{~h}$ was noted 
density (Lillelund \& Lasker 1971, Theilacker \& Lasker 1974, Bailey \& Yen 1983, Turner et al. 1985). The normal practice of performing functional response experiments in simple laboratory setups may produce a distorted picture of the full range of behavior of which invertebrate predators are capable (Hassell et al. 1977). Lipcius \& Hines (1986) found a sigmoid functional response for blue crabs Callinectes sapidus feeding on intertidal clams Mya arenaria buried in sandy substrate, and an asymptotic response when crabs fed on clams buried in mud. They argued that sand acted as a partial refuge to predation at low prey density. We propose that, in our system, sediment may also have acted as a partial refuge to predation at low egg densities.

Density compensation occurred at egg densities ranging from ca 1 to 3 eggs $\mathrm{cm}^{-3}$. At these low egg densities, the functional response of Calliopius leaviusculus to capelin egg density is likely to have only a very small stabilizing influence on capelin egg survival. Frank \& Leggett (1981) have shown that capelin larvae emerge synchronously from beach sediment coincident with onshore winds. Over the hatching interval, egg densities decrease by ca 10 to $20 \%$ after each storm event. At the end of the egg development season, egg densities decrease from ca 25 eggs $\mathrm{cm}^{-3}$ to near zero after a storm. Over most of the capelin egg development period therefore, the $C$. leaviusculus/capelin egg predator/prey system operates well above the compensatory and hence over the depensatory portion of the functional response curve.

Our experiments showed that handling time for amphipods ranging in size from 3.5 to $8 \mathrm{~mm}$ averaged $2.6 \mathrm{~min}$. This suggests that handling time did not limit egg consumption. The similarity between the longterm feeding rate ( 10.8 eggs amphipod $\left.{ }^{-1} \mathrm{~d}^{-1}\right)$, obtained from gut clearance trials where search time was minimized, and asymptotic satiation levels (10.83 eggs amphipod $^{-1}$ ) suggests that search time was not a constraint in functional response experiments at densities above 40 eggs $\mathrm{cm}^{-3}$. It should also be noted that the similarity between these 2 experiments implies that a pre-experiment starvation interval of $24 \mathrm{~h}$ did not markedly influence experimental results even though gut clearance requires an average of $36 \mathrm{~h}$.

Attack rate, mediated by search time at low egg density and by satiation and gut clearance rate at egg densities above 40 eggs $\mathrm{cm}^{-3}$, appears to be an important regulator of the rate of predation of amphipods on capelin eggs. Over most of the functional response curve (5.80 to 74.32 eggs $\mathrm{cm}^{-3}$ ), attack rate decreased with increasing egg density. Satiation occurred at a ration of ca 11 eggs amphipod ${ }^{-1}$, and potentially within $2 \mathrm{~h}$ of the initiation of feeding, at egg densities greater than 40 eggs $\mathrm{cm}^{-3}$. Our findings are consistent with those of Daag (1976) who noted alternate day feeding by Calliopius leaviusculus (mean size $=5 \mathrm{~mm}$ ) on the British Columbia (Canada) coast. He estimated a maximum ration of $0.360 \mathrm{mg}$ carbon amphipod ${ }^{-1} \mathrm{~d}^{-1}$ at $12^{\circ} \mathrm{C}$. This equates to 12.4 capelin eggs $\mathrm{d}^{-1}$ (Frank unpubl.), and conforms well with our asymptotic values.

At egg densities below 40 eggs $\mathrm{cm}^{-3}$, amphipods should require more time to reach satiation. However, we found no evidence that amphipods continued to feed for more than $8 \mathrm{~h}$ at these lower egg densities. There is growing interest in, and evidence of, allelopathic interactions in zooplankton (Helgen 1987). Contact water from the copepod Epischura navadensis inhibited the feeding rate of the copepod, Diaptomus tyrelli (Folt \& Goldman 1981); Folt (1986) found reduced feeding rates in high density Diaptomus; Daphnia hyalina cultured in water from high density $D$. hyalina or $D$. cucullata produced fewer eggs (suggesting lower feeding rates) compared with egg production by $D$. hyalina in lake water only (Seitz 1984). Helgen (1987) speculated that either prey mortality, or a substance released by invertebrates directly, could trigger the reduction in feeding rate observed in these studies. Since, in our experimental system, water exchange was allowed between low and high egg density containers, a reduction in feeding rate due either to high egg mortality, or to satiation in amphipods exposed to high egg densities, could have inhibited amphipod feeding in low egg density containers. This would have the net effect of synchronizing foraging time for feeding amphipods.

Synchronous foraging and a short feeding period can be advantageous to animals feeding in the intertidal where prolonged feeding would increase the possibility of stranding during ebb tide. This was suggested by Reid (1988) for the isopod Eurydice pulchra, which exhibits circatidal foraging. For Calliopius leaviusculus, we have shown that most foraging amphipods can reach satiation within 2 h at a density of ca 40 eggs $\mathrm{cm}^{-3}$. This density compares favorably with average capelin egg densities (June, July) at Bryant's Cove (38.9 eggs $\mathrm{cm}^{-3}, \mathrm{SE}=3.9$; Frank \& Leggett 1981) and elsewhere (Taggart \& Nakashima 1987).

\section{Impact of amphipod predation on capelin egg survival}

An estimate of the potential impact of Calliopius laeviusculus predation on the survival of capelin eggs can be generated by combining the results of experiments described here with estimates of amphipod densities and capelin egg development time in situ.

Egg mortality should increase with increased exposure to predation and therefore with egg development 
time. Average incubation temperatures decrease with the frequency and duration of tidal inundation over capelin egg beds, due to reduced exposure to higher air temperatures (Frank \& Leggett 1981). The location of eggs on the spawning beach could therefore potentially influence predation mortality.

Functional response experiments indicate that satiation occurs at 10.83 eggs amphipod ${ }^{-1}$ at densities above 40 eggs $\mathrm{cm}^{-3}$, and gut clearance experiments confirm that the long-term maximum feeding rate for amphipods is 10.8 eggs $\mathrm{d}^{-1}$. Assuming amphipods, whose average density on Bryant's Cove beach in 1988 was $1 \mathrm{~cm}^{-2}(\mathrm{SE}=0.20)$, eat 11 eggs $\mathrm{d}^{-1}$ over an average egg development period of 14,20 and $22 \mathrm{~d}$ for eggs located in the high tide, low tide and immediate subtidal zones respectively (Frank \& Leggett 1981), egg mortality due to amphipod predation would correspondingly be 32,46 and $50 \%$. Given these assumptions, eggs in the high tide zone would be expected to suffer $14 \%$ less predation than eggs in the low tide zone and predation would be highest subtidally. This exercise suggests, first, that there is a potential for high predation loss and, second, that rapid egg development could allow significantly more capelin to escape amphipod predation.

Clearly, predation by Calliopius laeviusculus on capelin eggs can significantly influence survival to the larval phase in this species. The predation estimates we obtained in this study are well within the range of estimates obtained for fish and other predators of benthic eggs. Pacific herring Clupea pallasi suffer egg losses of 30 to $50 \%$ as a result of predation by birds (Taylor 1964) and 16 to $52 \%$ losses from invertebrate predation (Palsson 1984) haddock Melanogrammus aeglefinus can consume $40 \%$ of the estimated annual production of Norwegian spring spawning herring Clupea harengus (Dragunsund \& Nakken 1973) and cannibalism by northern anchovy Engraulis mordax is reported to account for $17.2 \%$ of the egg production in this species (Hunter Kimbrell 1980). Capelin egg mortality due to flounder Pseudopleuronectes americanus predation was estimated at 1.6 to $5.0 \%$. (Frank \& Leggett 1984).

Frank \& Leggett (1984) speculated that the low rates of egg predation they observed may result from the shortened egg incubation times in the intertidal, as a consequence of the higher incubation temperatures which occur in this semi-terrestrial habitat. They also suggested that egg predation at offshore benthic spawning sites would be higher than in shallow water because of prolonged time to hatching at much lower temperatures. If correct, predation by amphipods and other invertebrates on the eggs of demersal spawners should not be overlooked as a potential regulator of population size in many marine fish species.
Acknowledgements. We thank Mike Paine for his constructive critisisms and comments on earlier versions of this manuscript and Joe Rasmussen for his insightful guidance on aspects of invertebrate behavior. We also thank Marc Bloom for excellent laboratory and field assistance. The work was supported by operating and stategic grants to W.C.L. from the Natural Sciences and Engineering Research Council of Canada. E.M.D. was supported by a Natural Sciences and Engineering Research Council post-graduate scholarship.

\section{LITERATURE CITED}

Bailey K. M. Houde E. D. (1989). Predation on eggs and larvae of marine fishes and the recruitment problem. Adv. mar. Biol. 25: 1-83

Bailey K. M. Yen J. (1983). Predation by a carnivorous marine copepod Euchaete elongata Esterly on eggs and larvae of the Pacific hake Merluccius productus. J. Plankton Res. 5: $71-82$

Boiclair, D., Leggett, W. C. (1988). An in-situ experimental evaluation of the Elliott and Persson and the Eggers models for estimating fish daily ration. Can. J. Fish. Aquat. Sci. 45: $138-145$

Chambers, C. C., Leggett, W. C. (1989). Event analysis applied to timing in marine fish ontogeny. Can. J. Fish. Aquat. Sci. 46: 1633-1641

Cohen, J. (1981). Statistical power analysis for the behavioral sciences. Academic Press, New York

Daag, M. J. (1976). Complete carbon and nitrogen budgets for the carnivorous amphipod Calliopius laeviusculus (Kroyer). Int. Revue ges. Hydrobiol. 61: 297-357

Dahlberg, M. D. (1979). A review of survival rates of fish eggs and larvae in relation to impact assessment. Mar. Fish. Rev. 41: $1-12$

Dragundsund, O., Nakken, O. (1973). Relationship of parent stock size and year-class strength in Norwegian spring herring. Rapp. P.-v. Réun. Cons. int. Explor. Mer 164: $15-29$

Fincham, A. A. (1970). Amphipods in the surf plankton. J. mar. biol. Ass. U.K. 50: 177-198

Folt, C. (1986). Experimental analysis of costs and benefits of zooplankton aggregation. In: Kerfoot, W. C., Sih, A. (eds.) Predation. Direct and indirect impacts on aquatic communities. Univ. Press of New England, Hanover, p. $300-314$

Folt, C., Goldman, C. R. (1981). Allelopathy between zooplankton: a mechanism for interference competition. Science 213: $1133-1135$

Frank, K. T., Leggett, W. C. (1981). Prediction of egg development and mortality rates in capelin (Mallotus villosus) from meteorological, hydrographic and biological factors. Can. J. Fish. Aquat. Sci. 38: 1327-1338

Frank, K. T., Leggett, W.C. (1984). Selective exploitation of capelin (Mallotus villosus) eggs by winter flounder (Pseudopleuronectes americanus): capelin egg mortality rates, and contribution of egg energy to the annual growth of flounder. Can. J. Fish. Aquat. Sci. 41: 1294-1302

Freund, J. R., Littell, R. C. (1981). SAS for linear models: a guide to the ANOVA and GLM procedures. SAS Institute Inc., Cary N. Carolina

Hassell, M. P. (1978). The dynamics of arthropod predatorprey systems. Princeton Univ. Press, Princeton, NJ

Hassell, M. P., Lawton, J. H., Beddington, J. R. (1977) Sigmoid functional responses by invertebrate predators and parasitoids. J. Anim. Ecol. 46: 249-262 
Helgen, J. C. (1987). Feeding rate inhibition in crowded Daphnia pulex. Hydrobiologia 154: 113-119

Hilden, M. (1988). Significance of the functional response of predators to changes in prey abundance in multispecies virtual population analysis. Can. J. Fish. Aquat. Sci. 45: $89-96$

Holling, C. S. (1959). The components of predation as revealed by a study of small mammal predation of the European pine sawfly. Can. Entomol. 91:293-320

Houde, E. D., Schekter, R. C. (1980) Feeding by marine fish larvae: developmental and functional responses. Environ. Biol. Fish. 5: 315-334

Hudon, C. (1983). Selection of unicellular algae by the littoral amphipods Gammarus oceanicus and Calliopius leaviusculus (Crustacea). Mar. Biol. 78: 59-67

Hunter J. R., Kimbrell, C. A. (1980). Egg cannibalism in the northern anchovy Engraulis mordax. Fish. Bull. U. S. 78: $811-816$

Ivlev, V. A. (1961). Experimental ecology on the feeding of fishes. Yale University Press, New Haven

Juliano, S. A., Williams, F. M. (1987). A comparison of methods for estimating the functional response parameters of the random predator equation. J. Anim. Ecol. 56: 641-653

Lillelund, K., Lasker, R. (1971). Laboratory studies of predation by marine copepods on fish larvae. Fish. Bull. U. S. 69: $655-667$

Lipcius, R. N., Hines, A. H. (1986). Variable functional response of a marine predator in dissimilar homogeneous microhabitats. Ecology 67 (5): 1361-1371

MacKenzie, B. R., Leggett. W. C., Peters, R. H. (1990). Estimating larval fish ingestion rates: can laboratory derived values be reliably extrapolated to the wild? Mar. Ecol. Prog. Ser. 67: 209-225

McGurk, M. D. (1986). Natural mortality of marine pelagic fish eggs and larvae: role of spatial patchiness. Mar. Ecol. Prog. Ser. 34: 227-242

McGurk, M. D. (1987). Natural mortality and spatial patchiness: reply to Gulland. Mar. Ecol. Prog. Ser 39: 201-206

Misra, R. K., Carscadden, J. E. (1984). Stock discrimination of capelin (Mallotus villosus) in the northwest Atlantic. J. Northw. Atl. Fish. Sci. 5: 199-205

Munk, P., Kiørboe, T (1985). Feeding behavior and swimming activity of larval herring (Clupea harengus) in relation to the density of copepod nauplii. Mar. Ecol. Prog. Ser. 24: $15-21$

Murdoch, W W., Oaten, A. (1975). Predation and population stability. Adv. Ecol. Res. 9; 2-131

Neter, J., Wasserman, W., Kutner, M. H. (1985). Applied linear statistical models, 2nd edn. Irwin, Homewood, llinois

Nikolskii, G. V (1969). Theory of fish population dynamics. Oliver and Boyd, Edinburgh

Palsson, W. A. (1984). Egg mortality upon natural and artificial substrata within Washington State spawning grounds of Pacific herring (Clupea harengus pallassi). M.S. thesis, University of Washington, Seattle

This article was presented by Professor C. H. Peterson, Morehead City, $N$. Carolina, USA
Peterman, R. M. (1977). A simple mechanism that causes collapsing stability regions in exploited salmonid populations. J. Fish. Res. Bd Can. 34: 1130-1142

Reid, D. G. (1988). The diurnal modulation of the circatidal activity rhythm by the feeding in the isopod Eurydice pulchra. Mar. Behav. Physiol. 6: 273-285

Rogers, D. T (1972) Random search and insect population models. J. Anim. Ecol. 41: 369-383

Royama, T (1971) A comparative study of models for predation and parasitism. Res. Popul. Ecol Suppl. 1. 1-91

SAS (1985). SAS/STAT guide for personal computers, version 6 edition. SAS Institute Inc Cary, N. Carolina

Seitz, A. (1984) Are there allelopathic interactions in zooplankton? Laboratory experiments with Daphnia. Oecologia 62: 94-96

Sharp, J. C., Able, K. W., Leggett, W. C., Carscadden, J. E (1978). Utility of meristic and morphometric characters for identification of capelin (Mallotus villosus) stocks in Canadian Atlantic waters. J. Fish. Res. Bd Can. 35: 124-130

Sih, A. (1984). Optimal behavior and density-dependent predation. Am. Nat. 123: 314-326

Smigielski, A. S., Arnold, C. R. (1972). Separating and incubating winter flounder eggs. Progve Fish Cult. 34: 113

Sokal, R. R., Rohlf, F. J. (1981). Biometry, the principles and practice of statistics in biological research, 2 nd edn. W. H. Freeman Co. New York

Steele, D. H., Steele, V. J. (1973). Some aspects of the biology of Calliopius laeviusculus (Crustacea, Amphipoda) in the north western Atlantic. Can. J. Zool. 51: 723-728

Taggart, C. T., Nakashima, B. S. (1987). The density of capelin (Mallotus villosus) eggs on spawning beaches in Conception Bay, Newfoundland. Can. Tech. Rep. Fish. Aquat. Sci. 1580

Taylor, F. H. C. (1964). Life history and present status of British Columbia herring stocks. Bull. Fish. Res. Bd Can. 143 $1-81$

Theilacker, G. H., Lasker, R. (1974). Laboratory studies of predation by euphausiid shrimps on fish larvae. In: Blaxter, J. H. S. (ed.) The early life history of fish. Springer Verlag, New York, p. 287-299

Trexler, J. C., McCulloch, C. E., Travis, J. (1988). How can the functional response best be determined? Oecologia 76 : $206-214$

Turner, J. T., Tester, P. A., Hettler, W. F. (1985). Zooplankton feeding ecology. A laboratory study of predation on fish eggs and larvae by the copepods Anomalocera ornata and Centropages typicus. Mar. Biol. 90: 1-8

Van Guelpen, L., Markle, D. F., Duggan, D. (1982) An evaluation of accuracy, precision, and speed of several zooplankton subsampling techniques. J. Cons. int. Explor. Mer 40: $226-236$

Werner, R. G., Blaxter, J. H. S. (1981) The effect of prey density on mortality, growth and food consumption in larval herring (Clupea harengus L.). Rapp. P.-v. Réun. Cons. int Explor. Mer 178: 405-408

Manuscript first received: June 6, 1990

Revised version accepted: October 29, 1990 